NOTAS

\title{
LARGA ES LA MEMORIA DE LOS PUEBLOS
}

Javier Meza*

Matar a un hombre no es nunca defender una doctrina sino matar a un hombre.

Nadie debe ser forzado a una convicción.

La convicción es libre.

Sebastián Castalión, 1551.

$\mathbf{P}$ más la historia del atropelllo y la violencia que la historia de la cordialidad. Pero dentro de esta historia casi siempre sobresale el heroísmo de la resistencia, individual o colectiva, en contra del abuso de poder. $\mathrm{Y}$ justo esto último narra analíticamente una interesante obra. ${ }^{1}$ Como bien señala la autora “...larga es la memoria de los pueblos", y dentro de esta amplitud ubica su esfuerzo por "rescatar del

* Departamento Académico de Estudios Generales, ITAM.

${ }^{1}$ Uchmany, Eva Alexandra, La vida entre el judaísmo y el cristianismo en la Nueva España 1580-1606. Archivo General de la Nación-Fondo de Cultura Económica,1992, México, con 131 ilustraciones de la autora. olvido de los siglos las vidas y actividades de las personas que formaban la comunidad criptojudía", o cristianos nuevos de origen portugués radicados en Nueva España a finales del siglo XVI y principios del XVII.

Normalmente se acepta que el $\mathrm{Re}$ nacimiento y el Mundo Moderno se originaron a partir de la caída de Constantinopla en poder de los Turcos en 1543. Sin embargo, este principio seguramente se originó un poco antes con la historia de una persecución: la expulsión de los judíos de la península ibérica. ${ }^{2}$ Esta es la historia

${ }^{2}$ A causa de su expulsión, "muchos se trasladaron a Italia, donde difundieron un nuevo interés en la lengua hebrea. $Y$ el entusiasmo por la tradición mística ju- 
NOTAS

de una intolerancia, y quizá de la peor de todas: la negación del libre albedrío. La persecución y expulsión de los judíos de España, decretada por los monarcas castellanos en 1492, provocó que la mayoría de ellos se refugiara en el vecino reino de Portugal, esperando correr allí con mejor suerte. Sin embargo, a los pocos años de haberse asilado nuevamente fueron expulsados (1497), ahora por el rey lusitano don Manuel. Tanto en un país como en otro la condición para no verse despojados de sus pertenencias y lanzados a tierras extrañas consistió en convertirse al cristianismo. Esta disposición fue motivada más por fines pragmáticos que humanitarios, pues ambas monarquías requerían de los conocimientos, profesiones y dinero de este singular pueblo industrioso. La mayoría de ellos eran astrónomos, médicos, filósofos, financieros y artesanos. Las razones de la persecución fueron siempre razones de Estado, y prueba de ello es que según conviniera al poder se establecía el perdón o la persecución. Al respecto la autora nos señala, por ejemplo, cómo el 23 de agosto de 1604 el papa Clemente VIII firmó un breve para absolver por corto tiempo de sus herejías y pecados a los cristianos nuevos de origen portugués, a cambio de la respetable suma de más de dos millones de cruzados. ${ }^{3}$ Para los que se convirtieron sinceramente es posible que

o sea la cábala", Yates, Frances A., La filosofía oculta en la época isabelina, 1982, México, F.C.E., p. 33.

${ }^{3}$ Uchmany, op. cit., p. 167. haya sido poco el sufrimiento, aun cuando tuvieron que padecer el hostigamiento y la afrenta por haber sidojudíos. Pero no fue así para quienes desde un principio tuvieron que quedarse o para los que huían y luego regresaban, fingiendo creer en una religión que no sentían. Todos ellos padecieron el terrible drama de "vivir de acuerdo con sus conciencias" en un contexto de represión y persecución inquisitorial. Persecución, por otro lado, nada nueva, pues así como es larga la suma de la existencia de la civilización judía (tres mil años), también es larga la historia de su represión. El hostigamiento oficial por parte de la religión hija, en contra de la religión madre, se inició en el Concilio de Elvira o Eliberis en el año 309. En ese momento se le prohibió al judío convivir con los cristianos y se le condenó a vivir apartado en sus barrios. Posteriormente, la segregación se reforzó obligándolos a utilizar estrellas o sombreros rojos o amarillos para diferenciarse. El uso de tan infamantes estigmas fue aprobado por el Concilio Laterano, en 1215. Pero el mayor absurdo en esta negra historia ocurrió durante el siglo $\mathrm{XV}$, cuando la iglesia española estableció los llamados Estatutos de Limpieza de Sangre. En ellos se decretó que toda persona que tuviese antepasados judíos no tenía la sangre limpia, y por lo mismo se le prohibió teóricamente desempeñar altos puestos dentro de la Iglesia y el poder público. ${ }^{4}$

${ }^{4} \mathrm{Al}$ respecto véase Sicroff, Albert A., Los estatutos de limpieza de sangre: Controversias entre los siglos XV y XVII, 1979, Madrid, Taurus. 


\section{NOTAS}

Tales actitudes descriminatorias siempre chocaron con la tolerancia que existió y existe en el seno de la cultura judía a propósito de las escuelas, sectas y facciones que han existido en su seno. Esta tolerancia sin lugar a dudas tiene su origen en su interesante inclinación por creer, practicar y defender las "múltiples explicaciones que pue. de tener un principio", inclinación que ineludiblemente desemboca en la práctica de respetar el libre albedrío. Este principio emparenta estrechamente con otras de sus máximas, como la de "devolver al hombre la libertad (y) la voluntad", y la obligación de "rescatar esclavos y cautivos".

Una vez expulsados de la península, su largo peregrinar los llevaría principalmente a lugares como África, Turquía, Holanda, India, Italia y América, pero también a regresar, como ya antes dijimos, a España y Portugal, pues como señala Uchmany muchos de ellos "no hallaban su lugar en parte alguna" y eran hombres que a la vez que "buscaban la vida jugaban con ella". La intrincada e interesante vida de los comerciantes Díaz Nieto (padre e hijo), y las de los místicos Luis de Carbajal, Manuel de Lucena y Sebastián Rodríguez, todos judíos de origen portugués, y procesados por el Santo Oficio de la Inquisición en Nueva España, sirven de punto de referencia para que alrededor de ellos la autora nos vaya tejiendo el desarrollo de múltiples historias inspiradas en el manejo del tiempo histórico sugerido por Fernand Braudel en relación con la corta, mediana y larga duración. Se trata de una historia un tanto global y comparativa en donde una a una se van sucediendo largas explicaciones, principalmente teóricas, religiosas, políticas y biográficas, que nos llevan y nos traen a lo largo del tiempo, sustentadas en fuentes bibliográficas, pero sobre todo en fuentes inquisitoriales de primera mano, pertenecientes a archivos de diversos lugares.

Alrededor de 1535 la familia Díaz Nieto, originaria de Oporto, huyó a Flandes y luego a Ferrara. Aquí nació Diego Díaz Nieto. El ducado de Ferrara durante el siglo XVI constituyó por su liberalidad un refugio seguro para los perseguidos a causa de su fe. En este ducado italiano, nos dice la autora, se había refugiado hacia 1492 el líder de los judíos españoles y portugueses Isaac Abrabanel, importante prestamista de los reyes católicos que se negó a ser convertido. Con sus ideas mesiánicas Abrabanel influyó en sus contemporáneos a través de su obra Migdal Yeshvot (Torre de las salvaciones), y fue padre nada menos que del famoso León Hebreo, autor de los Diálogos de amor (1535), ${ }^{5}$ obra que constituye uno de los pilares del llamado "platonismo renacentista", y es una sintesis de aristotelismo, neoplatonismo, cábala, mística árabe, mitología y astrología. En este ducado también fue editada por primera vez la Biblia en lengua castellana en 1535. La casa Abrabanel en Ferrara, junto con la familia Modena y Méndez, comerciantes de especias en Europa del norte, fungieron como mecenas para los re-

${ }^{s}$ 1986, Madrid, Tecnos. 
fugiados. A los 60 años el padre de Diego, Yaacov Ruy Díaz, a consecuencia de quebrar en su negocio, decidió junto con su hijo "ganarse la vida pidiendo limosna.en el mundo cristiano, con el pretexto de rescatar unos supuestos cautivos esclavizados por los infieles tur$\cos ^{\prime 6}$. Venecia, Roma, Florencia, Génova, Barcelona, Madrid y Oporto son algunos de los principales lugares recorridos por padre e hijo en su curioso peregrinar para decidir finalmente viajar a Nueva España, lugar al que tenían prohibido acercarse desde 1523 , y en donde serían capturados por la inquisición. El largo proceso inquisitorial contra Díaz Nieto, que la autora reproduce al final de su investigación, le permite reconstruir las costumbres y la vida de la comunidad judía de Ferrara, así comola de la comunidad criptojudía de origen portugués de Nueva España. Gracias al breve de Clemente VIII tanto el padre como el hijo lograron escapar de las manos inquisitoriales y regresar a Portugal, sin que se volviese a saber más de ellos.

La dureza del mundo circundante expresada en la estricta prohibición de manifestar libremente su concienciay su fe, llevó a la mayoría de estos perseguidos a acentuar su mesianismo. Su mirada se dirigía al futuro esperando el fin de los sufrimientos con la llegada del Mesías, y el advenimiento de la humanidad ideal. Según Uchmany, las esperanzas mesiánicas se encontraban presentes en las comunidades judías de Nueva España durante el siglo XVI, pero ya para la segunda mitad del siglo XVII flore-

\footnotetext{
${ }^{6}$ Uchmany, op. cit., p. 45.
}

cían en todas las juderías. Un claro ejemplo de mesianismo y de profundo amor a su fe lo constituyó Luis de Carvajal, el Mozo, alias Yoseph Lumbroso, sobrino del gobernador del nuevo reino de León. El mesianismo de Carvajal se inspiró sobre todo en los "13 artículos" de la religión judía propuestos por el filósofo Maimónides, en el Pentateuco, en los Salmos de David, en el libro del Esdras, y en los profetas como Isaías y Daniel con sus visiones apocalípticas. Fiel a su conciencia, Carvajal fue relajado y condenado a la hoguera en Nueva España en el auto de fe del 6 de diciembre de 1596. Junto con él murieron su entrañable amigo Manuel Lucena, Diego Enríquez, y su propia madre, doña Francisca de Carvajal, entre otros.

La resistencia de todos estos perseguidos a someterse a una religión oficial de Estado, y sólo obedecer a la voz de su conciencia y a su fe lleva a la autora a plantearnos una importante conclusión. A estos grupos la “...distinción y división entre la conciencia individual en cuestiones de fe y la religión oficial del Estado les permitieron transitar por todos los mundos sin perder su propia identidad. En otras palabras, los cristianos nuevos diferenciaron entre el comportamiento civil y el religioso mucho antes de que lo hicieran los pueblos europeos. De aquí y desde este punto de vista los podemos considerar los primeros hombres modernos."

${ }^{7}$ Uchmany, op. cit., p. 183.

Estudios 34, otoño 1993. 